\title{
PREVALÊNCIA E FATORES ASSOCIADOS À INFECÇÃO POR LENTIVÍRUS DE PEQUENOS RUMINANTES EM CAPRINOS NO ESTADO DO TOCANTINS
}

\author{
Pedro Alves de Moura Sobrinho, ${ }^{1}$ Taciana Rabelo Ramalho Ramos, ${ }^{1}$ Cláudio Henrique Clemente \\ Fernandes, ${ }^{1}$ Ana Claudia Campos, ${ }^{2}$ Luciana Menezes Costa ${ }^{3}$ e Roberto Soares Castro ${ }^{4}$ \\ 1. Médicos veterinários, doutores em Ciência Veterinária, pesquisadores, Fundação Universidade do Tocantins (UNITINSAGRO), Quadra 108 Sul, \\ Alameda 11, Lote 3, Palmas, TO, CEP 77020 122. E-mail: pedro.am@unitins.br \\ 2. Médica veterinária, mestranda em Ciência Veterinária, Universidade Federal Rural de Pernambuco, Recife, PE \\ 3. Médica Veterinária, autônoma \\ 4. Professor adjunto, Departamento de Medicina Veterinária, Universidade Federal Rural de Pernambuco, Recife, PE.
}

\section{RESUMO}

Objetivando estimar a prevalência de caprinos sororreagentes aos lentivírus de pequenos ruminantes (LVPR), através de uma amostragem não probabilística em rebanhos no Estado do Tocantins, analisaram-se 843 amostras de soros, mediante a utilização do teste de imunodifusão em gel de agarose (MICROIDGA) para a detecção de anticorpos anti-LVPR, sendo verificada uma frequência de animais sororreagentes de 2,7\% (23/843). Identificaram-se cinco focos: dois no município de Araguaína e um em cada um desses municípios: Babaçulândia, Filadélfia e Miracema do Tocantins. De acordo com a região, os resultados foram os seguintes: $10,0 \%(20 / 200)$ e $1,4 \%(3 / 207)$ para as microrregiões
Norte e Miracema, respectivamente. Entre as raças, a Saanen se apresentou com o maior percentual de animais sororreagentes, $11,7 \%(7 / 60)$. Para os animais sem raça definida, o percentual foi de $0,6 \%$ (2/310), e para a Anglo-Nubiana, de 3,0\% (14/466). De acordo com a idade, os animais com idade inferior e superior a 24 meses apresentaram $1,9 \%(6 / 314) 3,2 \%(17 / 529)$, respectivamente. Os machos apresentaram 2,4\% (4/166) de positivos e as fêmeas $2,8 \%$ (19/677). Os resultados indicam que os LVPR ocorrem com baixa prevalência no Estado do Tocantins, afetando principalmente animais da raça Saanen e da região norte.

PALAVRAS-CHAVES: Brasil, CAEV, epidemiologia, microimunodifusão.

\section{ABSTRACT}

\section{PREVALENCE AND ASSOCIATE FACTORS TO THE INFECTION FOR LENTIVIRUS OF SMALL RUMINANTS IN CAPRI- NE OF TOCANTINS STATE, BRAZIL}

The aim of this study was to estimate the prevalence of caprine blood reagents to small-ruminant lentiviruses (SRLV), through a non probabilistic sampling of herds in Tocantins State. In order to detect the anti-SRLV antibodies, 843 blood samples were analyzed using the microimmunodiffusion test in agarose gel - MICRO-IDGA. The frequency of blood reagent goats was $2.7 \%$ $(23 / 843)$. Five focus, being two in the city of Araguaína and one in each of the cities of Babaçulândia, Filadelfia and Miracema do Tocantins had been identified. The results were distributed according to micro-region in the following manner: 10.0 (20/200) and $1.4 \%$
(3/207) for the North and Miracema micro-regions, respectively. The Saanen was the breed with the highest percentage of blood reagent animals $(11.7 \% ; 7 / 60)$, the undefined breed animals $0.6 \%$ $(2 / 310)$ and Anglo-Nubian $(3.0 \% ; 14 / 466)$. Regarding age, $1.9 \%$ $(6 / 314)$ and $3.2 \%(17 / 529)$ of animals under and over 24 months of age, respectively, tested positive. $2.4 \%$ (4/166) of males and $2.8 \%$ $(19 / 677)$ of females tested positive. The SRLV infection occurs at a low prevalence among goats in Tocantins State, affecting mainly animal of the Saanen breed and from the north region.

KEY WORDS: Brazil, CAEV, epidemiology, microimmunodiffusion. 


\section{INTRODUÇÃO}

Análises da cadeia produtiva da caprinocultura nacional tem mostrado um grande potencial de expansão. Nesse sentido, é fundamental a preocupação com o estado sanitário dos rebanhos, uma vez que se têm intensificado as exigências sanitárias para o comércio de animais. Dessa forma, a melhoria das condições de higiene das instalações e a certificação de rebanhos livres para determinadas doenças podem resultar na agregação de valor aos animais e seus produtos (CASTRO \& MELO, 2001).

A ausência de um programa nacional de melhoramento genético essencial para a expansão da caprinocultura leiteira mostrou a necessidade de se importar animais de raças especializadas. Com as importações desses animais em países europeus, diversos problemas sanitários emergentes têm sido registrados, destacando-se as lentiviroses de pequenos ruminantes (LVPR) (ASSIS \& GOUVEIA, 1994; CASTRO, et al., 1994).

As LVPR são enfermidades infectocontagiosas de evolução lenta, causadas por um vírus da família Retroviredae e Subfamilia Lentivirinae, que se apresenta sob quatro formas clínicas: nervosa, respiratória, mamária e articular. A articular é a mais frequente em caprinos adultos, e com menor frequência observa-se leucoencefalomielite, em crias com idade entre um e quatro meses (DAWSON, 1980; EAST et al., 1993; CALLADO et al., 2001).

A principal forma de transmissão das LVPR é a ingestão de colostro ou leite de cabras infectadas. Porém, pode ocorrer a transmissão horizontal através das secreções e excreções, instrumentos e equipamentos contaminados e o contato de animais sadios com infectados por período prolongado (ADAMS et al., 1983; ALVES, 1999; PETERHANS et al., 2004). Essa infecção é insidiosa, vindo a apresentar sinais clínicos meses a anos após a infecção, enquanto a maioria dos animais não apresenta sintomatologia. No entanto, parâmetros de produção, principalmente em cabras leiteiras, são afetados (SMITH \& CUTLIP, 1988; GREENWOOD, 1995).

No Brasil, a primeira descrição sobre as LVPR em caprinos foi feita no Rio Grande do Sul, por MOOJEN et al. (1986). Estudos sorológicos com amostragem probabilística seguidos têm registrado a presença de animais positivos em vários Estados, principalmente nos rebanhos leiteiros de exploração comercial. As prevalências observadas variaram de 0,73\% a 43,0\%, em pesquisas nos seguintes Estados: Pernambuco (SARAIVA NETO et al., 1995), Ceará (PINHEIRO et al., 2001), São Paulo (LEITE et al., 2004), Paraíba (BANDEIRA, 2009), Rio Grande do Norte (SILVA et al., 2005), Bahia (OLIVEIRA et al., 2006), Piauí (SAMPAIO JR., 2007) e Rio de Janeiro (MOREIRA et al., 2007).

Tendo em vista o crescimento da caprinocultura no Tocantins e a falta de informação sobre as LVPR em caprinos no Estado, objetivou-se, com este trabalho, estimar a prevalência de caprinos sororreagentes para LVPR no Estado do Tocantins e verificar se existe associação entre microrregião, raça, idade, sexo, sistema de criação e criatórios com associação de espécie com a ocorrência de LVPR.

\section{MATERIAL E MÉTODOS}

O Estado do Tocantins, com uma área de 286.706 $\mathrm{Km}^{2}$, situa-se na Região Norte do País, na Amazônia Legal, e tem como coordenadas geográficas longitude de $46^{\circ} 00^{\prime}$ e $51^{\circ} 00^{\prime}$ de Greenwich e latitude de $05^{\circ} 00^{\prime}$ e $13^{\circ} 00^{\prime}$ S. Possui vegetação bastante variada, desde o campo cerrado, cerradão, campos limpos ou rupestres a floresta equatorial de transição, sob forma de "mata de galeria". O clima é tropical semiúmido, com temperatura média anual de $26^{\circ} \mathrm{C}$. As precipitações pluviais variam de $1.500 \mathrm{~mm}$ a $1.800 \mathrm{~mm} /$ ano e caracterizam-se por uma distribuição que define dois períodos, um seco de maio a agosto, outro chuvoso, correspondendo aos meses de setembro a maio (NASCIMENTO, 2007).

A prevalência de LVPR em caprinos foi estimada com base em um estudo por amostragem não probabilística, envolvendo os municípios de Araguatins, Araguaína, Xambioá, Babaçulândia, Filadélfia, Barra do Ouro, Araguacema, Dois Irmãos do Tocantins, Miracema do Tocantins, Pium, Paraíso, Palmas, Natividade, Dianópolis e Ponte Alta do Bom Jesus (Figura 1). O número de animais utilizados nesta pesquisa foi calculado com auxílio do programa Epi-Info na versão 3.3.2 (DEAN et al., 1992), por meio da seguinte fórmula, descrita por KISH (1965):

$$
\mathrm{N}=\mathrm{Z} . \mathrm{Z}[\mathrm{P}(1-\mathrm{P})] / \mathrm{D} . \mathrm{D} \text {, }
$$

em que: 
№ - número de amostras para estimar prevalência em uma população infinita;

$\mathrm{P}$ - prevalência esperada $(5 \%)$;

$\mathrm{Z}$ - fator determinante do grau de confiança de $90 \%$ $(\mathrm{Z}=1,64) \mathrm{e}$

D - erro amostral $(25 \% \mathrm{P})$.

Assim, obteve-se "N" igual a 818 amostras. O número de amostras colhidas por propriedades variou de 16 a 30, totalizando 843 em 29 propriedades. A idade dos animais foi estimada com base no número de dentes que o animal apresentava: primeira muda (menos de 24 meses) e mais de duas mudas (mais de 24 meses) (JARDIM, 1985).

Colheu-se o sangue por meio de venopunção da jugular, utilizando sistema de vácuo. Após a retração do coágulo, as amostras foram centrifugadas a $800 \mathrm{~g}$, durante dez minutos e transferidas para tubos de congelamento $(1,5 \mathrm{~mL})$, que permaneceram a $-20^{\circ} \mathrm{C}$ até $\mathrm{o}$ momento do processamento.

Para a detecção de anticorpos contra LVPR, foi utilizada a microtécnica de imunodifusão em gel de ágar (IDGA), utilizando kit comercial, ${ }^{1}$ composto de antígeno, soro-padrão positivo e solução de agarose a 1\% em tampão borato, segundo as recomendações do fabricante.

Para análise dos dados, utilizou-se o teste Quiquadrado de Pearson ou o teste Exato de Fisher, quando não se verificaram as condições para utilização do teste Qui-quadrado. O nível de significância utilizado na decisão dos testes estatísticos foi de 5,0\%. Para a obtenção dos cálculos estatísticos, empregou-se o programa Epi-Info versão 3.2.2 (DEAN et al., 1992).

\section{RESULTADOS E DISCUSSÃO}

Das 843 amostras séricas examinadas pelo teste de IDGA para pesquisa de anticorpos contra LVPR, 23 $(2,7 \%)$ foram positivas. Identificaram-se cinco focos, sendo dois no município de Araguaína e um em cada um destes municípios: Babaçulândia, Filadélfia e Miracema do Tocantins (Figura 1). Dos 29 rebanhos estudados, cinco $(17,2 \%)$ apresentaram, pelo menos, um animal sororreagente.

A baixa prevalência encontrada nesta pesquisa pode ser explicada, possivelmente, pela recente for-

1 - Biovetech - Indústria e Comércio de Produtos Biotecnológicos Ltda.-ME, Recife, PE. mação dos rebanhos no estado, composto basicamente por Anglo-Nubiano e animais sem raça definida (SRD), que, segundo SARAIVA NETO (1995), têm apresentado prevalências inferiores aos animais de raças leiteiras de origem europeia. E também pela não adoção, nas propriedades pesquisadas, de práticas que tendem a aumentar o risco de transmissão horizontal, como o confinamento e a utilização de mamadeira coletiva (ADAMS et al., 1983; ALVES, 1999). Todavia, esses resultados são considerados importantes, pela possibilidade de disseminação do LVPR para outros plantéis de caprinos. Além disso, a intensificação dos sistemas de criação, à medida que se busca aumentar a produtividade, poderá proporcionar condições para disseminação do vírus (COSTA et al., 2007).

Encontraram-se animais sororreagentes para LVPR em duas microrregiões - 10,0\% entre os animais da microrregião Norte e $1,4 \%$ entre os animais de Miracema (Tabela 1) -, mostrando resultados que indicam associação significativa entre a prevalência de LVPR com as microrregiões $(p<0,05)$. A alta positividade encontrada na microrregião Norte deve-se, possivelmente, ao fato de os animais pertencerem a rebanhos de exploração para a produção de leite.

Nas propriedades estudadas, registraram-se apenas cinco raças (Anglo-Nubiano, Saanen, sem raça definida (SRD), Boer e Jamnapari), o que demonstra a recente adesão à caprinocultura, por parte dos criadores, no Estado. Verificou-se que a positividade para LVPR foi mais elevada entre os animais da raça Saanen com 11,7\% (7/60), seguida da raça Anglo-Nubiano, $3,0 \%$ (14/452), e de $0,6 \%$ (2/310) nos animais de sem raça definida (SRD). De acordo com a análise dos resultados, comprovou-se associação significante entre raça e a ocorrência de LVPR $(\mathrm{P}<0,05)$ (Tabela 2$)$.

Uma das causas de menor prevalência nos animais sem raça definida (SRD), em comparação com os animais puros, pode ser o sistema de manejo. Isso porque algumas práticas com tendência a aumentar o risco de transmissão horizontal, como o confinamento e a utilização de mamadeiras coletivas, ocasionalmente adotadas em algumas propriedades, são geralmente empregadas no manejo de rebanhos puros leiteiros (SARAIVANETO et al., 1995). A presença, na quase totalidade, das LVPR entre os animais leiteiros pode representar risco de disseminação do agente para os animais sem raça de definida (SRD) (PINHEIRO et al., 2001; BANDEIRA, 2005). 


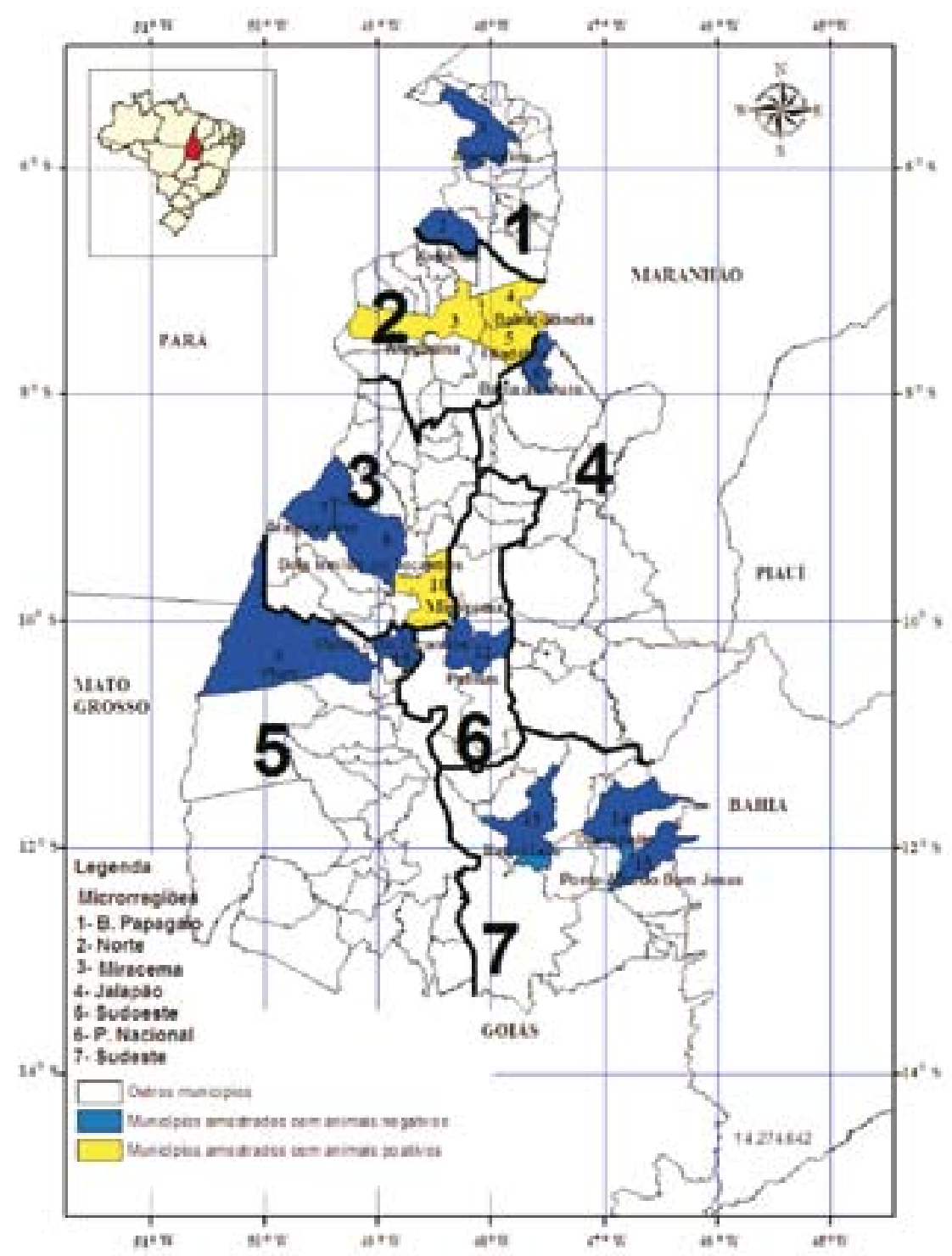

FIGURA 1. Representação geográfica dos municípios do Estado do Tocantins com amostra para LVPR em caprinos.

TABELA 1. Distribuição de frequência de caprinos positivos à microimunodifusão em gel de ágar (MICRO-IDGA) para lentivírus de pequenos ruminantes, por microrregião em rebanhos caprinos do Estado do Tocantins, 2006

\begin{tabular}{|c|c|c|c|c|c|}
\hline \multirow{3}{*}{ Microrregião } & & \multicolumn{4}{|c|}{ MICRO - IDGA } \\
\hline & & \multicolumn{2}{|c|}{ Positivo } & \multicolumn{2}{|c|}{ Negativo } \\
\hline & $\mathrm{N}$ & $\mathrm{n}$ & $\%$ & $\mathrm{n}$ & $\%$ \\
\hline Bico do Papagaio & 46 & 0 & 0,0 & 46 & 100,0 \\
\hline Norte & 200 & 20 & 10,0 & 180 & 90,0 \\
\hline Jalapão & 60 & 0 & 0,0 & 60 & 100,0 \\
\hline Miracema & 207 & 3 & 1,4 & 204 & 98,6 \\
\hline Sudoeste & 90 & 0 & 0,0 & 90 & 100,0 \\
\hline Porto Nacional & 150 & 0 & 0,0 & 150 & 100,0 \\
\hline Sudeste & 90 & 0 & 0,0 & 90 & 100,0 \\
\hline Total & 843 & 23 & 2,7 & 820 & 97,3 \\
\hline
\end{tabular}

$\mathrm{P}=0,0001$, teste qui-quadrado 
TABELA 2. Distribuição de frequência de ovinos positivos à microimunodifusão em gel de ágar (MICRO-IDGA) para lentivírus de pequenos ruminantes, raça no Estado do Tocantins, 2006

\begin{tabular}{|c|c|c|c|c|c|}
\hline \multirow{3}{*}{ Raça } & & \multicolumn{4}{|c|}{ MICRO - IDGA } \\
\hline & & \multicolumn{2}{|c|}{ Positivo } & \multicolumn{2}{|c|}{ Negativo } \\
\hline & $\mathrm{N}$ & $\mathrm{n}$ & $\%$ & $\mathrm{n}$ & $\%$ \\
\hline SRD & 310 & 2 & 0,6 & 308 & 99,4 \\
\hline Anglo-Nubiano & 466 & 14 & 3,0 & 452 & 97,0 \\
\hline Saanen & 60 & 7 & 11,7 & 53 & 88,3 \\
\hline Total & 843 & 23 & 2,7 & 813 & 97,3 \\
\hline
\end{tabular}

$\mathrm{P}=0,0001$, através do teste qui-quadrado

Com relação à idade dos animais, a prevalência de animais positivos para as LVPR foi de $3,2 \%$ entre os animais com faixa etária entre a segunda e a quarta mudas, e de $1,9 \%$ entre os animais na faixa etária até a primeira muda. A análise dos resultados não comprovou associação significativa entre faixa etária e a ocorrência de LVPR (p>0,05) (Tabela 3). A superioridade da frequência de positivos entre os animais mais velhos pode ser explicada, uma vez que se trata de uma enfermidade de evolução lenta, pelo maior tempo de exposição dos animais ao vírus (MCGUIRE, 1987). O tempo para o animal produzir anticorpos a níveis detectáveis no teste IDGA é demorado, podendo ocorrer até dezoito meses após a detecção pelo PCR ou até mesmo não acontecer (WAGTER et al., 1998).

Na Tabela 4, estão dispostos os resultados dos testes sorológicos referentes ao sexo. A prevalência de animais positivos para LVPR foi apenas $0,4 \%$ mais elevada entre as fêmeas do que entre os machos $(2,8 \%$ $x 2,4 \%$ ) e não se comprovou associação significativa entre sexo e a ocorrência de LVPR $(\mathrm{p}>0,05)$. Esses resultados corroboram os de CRAWFORD \& ADAMS
(1981) e SARAIVA NETO (1995), que afirmam não existir fatores relacionados ao sexo que predisponham à infecção pelo vírus da LVPR. No entanto, FERNANDES et al. (2003) relatam que o maior tempo de permanência das fêmeas no rebanho e o fato de se manterem juntas todo o tempo na mesma baia (ao passo que os machos reprodutores geralmente são mantidos em baias separadas) são fatores que contribuem para disseminação do vírus entre as fêmeas.

De acordo com o sistema de manejo, observaramse animais positivos em $6,6 \%(1 / 15)$ e $28,4 \%(4 / 14)$ das propriedades que adotam o sistema de criação extensivo e semiextensivo, respectivamente (Tabela 5). A frequência de positivos no sistema semiextensivo foi superior, mas à análise não se observou diferença significativa entre o sistema de criação e a ocorrência de animais positivos por rebanhos $(p>0,05)$. O sistema de criação dos animais é fator importante na disseminação do vírus, por se considerar a aglomeração um fator favorável à disseminação dos LVPR (CASTRO \& MELO, 2001; FERNANDES et al., 2003).

TABELA 3. Distribuição de frequência de caprinos positivos à microimunodifusão em gel de ágar (MICRO-IDGA) para lentivírus de pequenos ruminantes, por idade (muda) no Estado do Tocantins, 2006

\begin{tabular}{lcccccc}
\hline & & \multicolumn{3}{c}{ MICRO - IDGA } \\
\hline Idade (muda) & \multicolumn{2}{c}{ Positivo } & & Negativo \\
\hline & $\mathrm{N}$ & $\mathrm{n}$ & $\%$ & $\mathrm{n}$ & \\
\hline Até primeira- & 314 & 6 & 1,9 & 308 & 98,1 & 96,8 \\
Entre a segunda e a quarta & 529 & 17 & 3,2 & 2,7 & 820 & 97,3 \\
Total & 843 & 23 & & & & \\
\hline
\end{tabular}

$\mathrm{P}=0,2616$, através do teste qui-quadrado 
TABELA 4. Distribuição de frequência de caprinos positivos à microimunodifusão em gel de ágar (MICRO - IDGA) para lentivírus de pequenos ruminantes, por sexo no Estado do Tocantins, 2006

\begin{tabular}{|c|c|c|c|c|c|}
\hline \multirow{3}{*}{ Sexo } & & \multicolumn{4}{|c|}{ MICRO - IDGA } \\
\hline & & \multicolumn{2}{|c|}{ Positivo } & \multicolumn{2}{|c|}{ Negativo } \\
\hline & $\mathrm{N}$ & $\mathrm{n}$ & $\%$ & $\mathrm{n}$ & $\%$ \\
\hline Machos & 166 & 4 & 2,4 & 162 & 4 \\
\hline Fêmeas & 677 & 19 & 2,8 & 658 & 19 \\
\hline Total & 843 & 23 & 2,7 & 820 & 23 \\
\hline
\end{tabular}

$\mathrm{P}=1,000$, teste Exato de Fisher.

TABELA 5. Distribuição de frequência de caprinos positivos à microimunodifusão em gel de ágar (MICRO - IDGA) para lentivírus de pequenos ruminantes, por sistema de criação no Estado do Tocantins, 2006

\begin{tabular}{lcccccc}
\hline & \multicolumn{3}{c}{ MICRO - IDGA } \\
\hline Sistema de criação & \multicolumn{3}{c}{ Positivo } & \multicolumn{2}{c}{ Negativo } \\
\hline Extensivo & N. ${ }^{\circ}$ de rebanhos & $\mathrm{n}$ & $\%$ & $\mathrm{n}$ & 14 \\
Semiextensivo & 15 & 1 & 6,6 & 28,6 & 10 & 73,4 \\
Total & 14 & 4 & 17,2 & 24 & 82,8 \\
\hline
\end{tabular}

$\mathrm{P}=0,1432$, através do teste Exato de Fisher.

Na Tabela 6, constam os resultados por criatórios segundo associação ou não de espécies. Nos criatórios que criam apenas caprinos, o porcentual de animais sororrreagentes foi $18,7 \%(3 / 16)$ e nos que criam caprinos e ovinos, $15,4 \%(2 / 15)$. A análise dos resultados não mostrou diferença significativa $(p>0,05)$ entre o manejo associado caprino + ovino ou apenas caprinos e a ocorrência de lentivírus nos rebanhos estudados (Tabela 6). Todavia, estudos filogenéticos indicam a existência de transmissão entre caprinos e ovinos (OLIVER et al., 1985; CASTRO et al., 1999; SHAH et al., 2004).

TABELA 6. Distribuição de frequência de caprinos positivos à microimunodifusão em gel de ágar (MICRO - IDGA) para lentivírus de pequenos ruminantes, por criatório com associação de espécies no Estado do Tocantins, 2006

\begin{tabular}{|c|c|c|c|}
\hline & & & \\
\hline Espécie & $\begin{array}{c}\mathrm{N} .{ }^{\circ} \text { de } \\
\text { rebanhos }\end{array}$ & $\begin{array}{l}\text { Positivo } \\
\mathrm{n} \quad(\%)\end{array}$ & $\begin{array}{c}\text { Negativo } \\
\mathrm{n}(\%)\end{array}$ \\
\hline Caprino & 16 & $3 \quad(18,7)$ & $13(81,3)$ \\
\hline Caprino + ovino & 13 & $2 \quad(15,4)$ & $11(84,6)$ \\
\hline Total & 29 & $(17,2)$ & $24(82,8)$ \\
\hline
\end{tabular}

$\mathrm{P}=0,6038$, através do teste Exato de Fisher.

\section{CONCLUSÃO}

O LVPR está presente, com baixa prevalência, nos rebanhos de caprinos no Estado do Tocantins, principalmente na microrregião Norte e nos animais da raça Saanen. Esses dados mostram a importância da implantação de medidas de controle das lentiviroses de pequenos ruminantes no Estado. 


\section{AGRADECIMENTOS}

Ao Conselho Nacional de Desenvolvimento Científico e Tecnológico (CNPq), pelo financiamento do presente trabalho.

\section{REFERÊNCIAS}

ADAMS, D. S.; KLEVJER-ANDERSON, P.; CARLSON, B. S.; MCGUIRE, T. C. Transmission and control of caprine arthritisencephalitis virus. American Journal Veterinary Research, v. 44, p.1670-1675, 1983 .

ALVES, F. S. F. Fatores de risco e transmissão da artrite encefalite caprina a vírus. Sobral: Embrapa Caprino, 1999. 15 p. (Embrapa Caprino. Documento, 29).

ASSIS, A. P. M. V.; GOUVEIA, A. M. G. Evidência de lentivirus (Maedi-Visna/CAE) em rebanho nos Estados de MG, RJ, BA e CE. In: CONGRESSO BRASILEIRO DE MEDICINA VETERINÁRIA, 23., 1994, Recife. Anais... Recife: Sociedade Brasileira de Medicina Veterinária, 1994. p. 104.

BANDEIRA, D. A.; CASTRO, R.; AZEVEDO, E. O.; MELO, L. S. S.; MELO, C. B. Seroprevalence of caprine arthritis-encephalitis virus in goats in the Cariri region, Paraiba state, Brazil. The Veterinary Journal, v. 180, p. 399-401, 2009.

CAllado, A. K. C.; CASTRO, R. S.; TEIXEIRA, M. F. S. Lentivírus de pequenos ruminantes (AEV e Maedi-Visna): revisão e perspectivas. Pesquisa Veterinária Brasileira, v. 21, n. 3, p. 87-97, 2001.

CASTRO, R. S.; GREENLAND, T.; LEITE, R. C.; GOUVEIA, A. M. J.; MORNEX, J. F.; CORDIER, G. Conserved sequence motifs involving the tat reading frame of Brazilian caprine lentiviruses indicate affiliations to both caprine arthritisencephalitis virus and visna-maedi virus. Journal General Virology, v. 80, p. 1583-1589, 1999.

CASTRO, R. S.; MELO, L. E. H. CAEV e Maedi-Visna: importância na saúde e produtividade de caprinos e ovinos e a necessidade de seu controle no Nordeste brasileiro. Ciência Veterinária nos Trópicos, v. 4, n. 2/3, p. 315-320, 2001.

CASTRO, R. S.; NASCIMENTO, S. A.; R. C.; ABREU, S. R. Evidência sorológica da infecção pelo vírus da artrite encefalite caprina em caprinos leiteiros no Estado de Pernambuco. Arquivo Brasileiro de Medicina Veterinária e Zootecnia, v. 46, n. 5, p. 571-572, 1994

COSTA, L. S. P.; LIMA, P. P.; CALLADO, A. K. C.; NASCIMENTO, S. A.; CASTRO, R. S. Lentivírus de pequenos ruminantes em ovinos Santa Inês: isolamento, identificação pela PCR e inquérito sorológico no Estado de Pernambuco. Arquivo Instituto Biológico, v. 74, n. 1, p. 11-16, 2007.

CRAWFORD, T. B.; ADAMS, D. S. Caprine arthritis-encephalitis: clinical features and presence of antibody in selected populations. Journal of American Veterinary Medicine Association, v. 178, p. 713-719, 1981.

DAWSON, M. Pathogenesis of maedi visna. Veterinary Record, v. 120 , p. 451-454, 1980.

DEAN, A. G.; DEAN, J. A.; BURTON, A. H. E.; DICKER R. C. Epi info, version 6: a word processing, database and statistic program for epidemiology on micro-computers. Atlanta, Georgia, Center for Disease Control, 1992. 302 p. Disponível em: http:// www.cdc.gov/EpiInfo/biblio.htm

EAST, N. E.; ROWE, W. J.; DAHLBERG, J. E.; THEILEN, G. H.; PEDERSOEN, N. C. Models of transmission of caprine arthritis encefalites virus infection. Small Ruminant, v. 10, p. 251-262,1993.

FERNANDES, M. A.; ARAÚJO, W. P.; CASTRO, R. S. Prevalência da infecção pelo vírus Maedi-Visna em ovinos da microregião grande São Paulo. Ciência Veterinária nos Trópicos, v. 6, n. 1, p. 23-28, 2003.

GREENWOOD, P. L. Effects of caprine artrhitis-encephalitis virus on productivity and health of dairy goats in New South Wales, Australia. Preventive Veterinary Medicine, v. 22, p. 71-78, 1995.

JARDIM, W. R. Criação de caprinos. 11. ed. São Paulo: Nobel, 1985. $238 \mathrm{p}$.

KISH, L. Survey sampling. New York: John Wiley e Sons Inc, $1965.634 \mathrm{p}$.

LEITE, B. L. S.; MODOLO, J. R.; PADOVANI, C. R.; STASCHISINI, A. V. M; CASTRO, R. S.; SIMÕES, L. B. Avaliação da taxa de ocorrência da artrite encefalite caprina a vírus pelas regionais do Escritório de Defesa Agropecuária do Estado de São Paulo, Brasil, e seu mapeamento por meio de sistemas de informações geográficas. Arquivo Instituto Biológico, v. 71, n. 1, p. 21-26, 2004.

MCGUIRE, T. C. The imune response to viral antigens as adeterminant of arthritis in caprine arthritis-encephalitis infection. Veterinary Immunology and Immunopathology, v. 17, n. 1, p. 465-470, 1987.

MOOJEN, V.; SOARES, H. C.; RAVEZZOLO, A. P.; PIZZOL, M.; GOMES, M. Evidência de infecção pelo Lentivirus (MadeiVisna/artrite-encefalite caprina) em caprinos do Rio Grande do Sul, Brasil. Arquivos da Faculdade de Veterinária da UFRGS, v. 14, p. 77-78, 1986. 
MOREIRA, M. C.; OELEMANN, W. M. R.; LILENBAUM, W. Dados sorológicos da artrite encefalite caprina no Estado do Rio de Janeiro e avaliação do uso do índice clínico como ferramenta de diagnóstico. Revista Brasileira de Medicina Veterinária, v. 29, n. 2, p. 51-53, 2007.

NASCIMENTO, J. B. Conhecendo o Tocantins: história e geografia. 5. ed. Goiânia: ASA, 2007.

OLIVEIRA, M. M. M.; CASTRO, R. S.; CARNEIRO, K. L; NASCIMENTO, S. A.; CALLADO, A. K. C.; ALENCAR, C. S. A.; COSTA, L. S. P. Anticorpos contra lentivírus de pequenos ruminantes em caprinos e ovinos em abatedouros do estado de Pernambuco. Arquivos Brasileiros de Medicina Veterinária e Zootecnia, v. 58, n. 5, p. 947-949, 2006.

OLIVER R.; C. A.; McNIVEN, R.; P. W.; ROBATI, G. Infection of lambs with CAEV by feeding milk from infected goats. Veterinary Record, v. 19, p. 83-90, 1985.

PETERHANS, E.; GREENLAND, T.; BADIOLA, C.; HARKISS, G.; BERTONI, G.; AMORENA, B.; ELIASZEWICZ, M.; JUSTE, A.; KRABNIG, R.; LAFONT, J. P.; LENIHAN, P.; PETURSSON, G.; PRITCHARD, G. THORLEY, J.; VITU, C.; MORNEX, J. F.; PEPIN, M. Routes of transmission and consequences of small ruminant lentiviruses (SRLVs) infection and eradication schemes. Veterinary Research, v. 35, p. 257-274, 2004.

PINHEIRO, R. R.; GOUVEIA, A. M. G.; ALVES, F. S. F. Prevalência da infecção pelo vírus da artrite encefalite caprina no Estado do Ceará, Brasil. Ciência Rural, v. 31, p. 449-454. 2001.
SAMPAIO JÚNIOR, A. Soroprevalência das lentiviroses de pequenos ruminantes em caprinos e ovinos no município de Teresina, Piauí, Brasil. 2007. 68 f. Dissertação (Mestrado em Ciência Animal) - Universidade Federal do Piauí, Teresina, 2007.

SARAIVA NETO, A. O.; CASTRO, R. S.; BIRGEL, E. H.; NASCIMENTO, S. A. Estudo soro-epidemiológico da artrite encefalite caprina em Pernambuco. Pesquisa Veterinária Brasileira, v. 15, n. 4, p. 121-124, 1995.

SHAH, C.; BÖNI, J.; HUDER, J. B.; VOGT. H. R.; MUHLHERR, J.; ZANONNI, R.; MISEREZ,R.; LUTZ, H.; SOHUPBACH, J. Phylogenetic analysis and reclassification of caprine and ovine lentiviruses based on 104 new isolates: evidence for regular sheepto-goat transmission and world propagation through livestock trade. Virology, n. 319, p. 12-26, 2004.

SILVA, J. S.; CASTRO, R. S.; MELO, C. B.; FEIJO, F. M. C. Infecção pelo vírus da artrite encefalite caprina no Rio Grande do Norte. Arquivo Brasileiro de Veterinária e Zootecnia, v. 57, n. 6, p. 726-731, 2005.

SMITH, M.C.; CUTLIP, R. Effects of infection with caprine arthritis-encephalitis virus on milk production in goats. Journal of American Veterinary Medicine Association, v. 193, p. 63-67, 1988.

WAGTER, L. H.; JANSEN, A.; BLEUMINK-PLUYM, N. M.; LENSTRA, J.A.; HOUWERS, D. J. PCR detection of lentiviral gag segments DNA in the white blood cells of sheep and goats. Veterinary Research Communications, v. 22, p. 355-362, 1998.

Protocolado em: 21 maio 2008. Aceito em: 15 ago. 2009. 